GEOUSP - Espaço e Tempo, São Paulo, No 28, pp. 197 - 218, 2010

\title{
Conflictos territoriales en ámbitos rurales de la Argentina actual ${ }^{1}$
}

\author{
Mabel Manzanal* y Mariana Arzeno**
}

\begin{abstract}
Resumen
En el ámbito rural en Argentina se percibe, desde la década de 1990, un aumento de la conflictividad social. Surgen localmente movimientos, conflictos y demandas vinculadas con la apropiación y uso de los recursos del territorio (tierra, agua, minerales, bosques, infraestructura, etc.) o con las consecuencias ambientales del accionar del hombre sobre el mismo (contaminación, deforestación, inundaciones). Sin embargo, y a pesar que muchos de ellos han tomado estado público, estos conflictos en su mayoría se ignoran o se minimizan. Sin embargo, otra trascendencia tuvo el que se desencadenó en marzo de 2008, conocido como el conflicto "del campo" o "agrario". Este conflicto estuvo atravesado por múltiples contradicciones, discrepancias y confusiones promovidas por ambos sectores en pugna (referentes del sector agrario y gobierno). Y lejos de representar una problemática universal del "campo", no fue más que la expresión de una disputa al interior de los sectores dominantes.

En este trabajo, a partir de estudios de caso en las provincias de Salta y Misiones, aplicando metodologías cualitativas y desde una perspectiva analítica que visualiza los conflictos como expresiones de luchas de poder por los recursos del territorio, nos proponemos mostrar las contradicciones y consecuencias territoriales de conflictos asociados tanto con disputas por el poder hegemónico como los vinculados con resistencias al modelo de desarrollo dominante y excluyente.
\end{abstract}

\section{Resumo}

No âmbito rural na Argentina percebe-se, desde a década de 1990, um aumento dos conflitos sociais. Surgem localmente movimentos, lutas e demandas vinculadas com a apropriação e uso dos recursos do território (terra, água, minerais, bosques, infraestrutura, etc.) ou com as consequências ambientais da ação do homem sobre o mesmo (contaminação, desmatamento, inundações). Todavia, e apesar de muitos deles terem se tornado públicos, esses conflitos em sua maioria são ignorados ou se minimizam. Entretanto, o que se desencadeou em março de 2008, conhecido como o conflito do campo ou agrário, teve outra transcendência. Este conflito foi atravessado por múltiplas contradições, discrepâncias e confusões promovidas por ambos os setores em luta (referentes do setor agrário e governo). E longe de representar uma problemática universal do campo, não foi mais do que a expressão de uma disputa no interior dos setores dominantes. Neste trabalho, a partir de estudos de caso nas províncias de Salta e Misiones, aplicando metodologias qualitativas e a partir de uma perspectiva analítica que visualiza os conflitos como expressões de lutas de poder pelos recursos do território, propomos mostrar as contradições e consequências territoriais dos conflitos associados tanto às disputas pelo poder hegemônico como os vinculados a resistências ao modelo de desenvolvimento dominante e excludente.

\footnotetext{
* Mabel Manzanal es Economista, Doctora de la Universidad de Buenos Aires, Investigadora Principal del CONICET, Directora del Programa de Economías Regionales y Estudios Territoriales (PERT) del Instituto de Geografía, Facultad de Filosofía de la UBA

**Mariana Arzeno es Geógrafa, Doctora de la Universidad de Buenos Aires, Investigadora Asistente del CONICET, Integrante del PERT, Instituto de Geografía, Facultad de Filosofía de la UBA.
} 


\section{Introducción}

En el ámbito rural en Argentina se percibe, desde la década de 1990, un aumento de la conflictividad social. Surgen localmente movimientos, conflictos y demandas vinculadas con la apropiación y uso de los recursos del territorio (tierra, agua, minerales, bosques, infraestructura, etc.) o con las consecuencias ambientales del accionar del hombre sobre el mismo (contaminación, deforestación, inundaciones). Sin embargo, y a pesar que muchos de ellos han tomado estado público, se trata de conflictos que en su mayoría se ignoran o minimizan. Y en particular, esto sucede en las grandes urbes donde se concentra la mayor parte de la población argentina y el poder político, económico e institucional del país. Sin embargo, otra trascendencia tuvo el conflicto que se desencadenó en marzo de 2008. Conocido como conflicto "del campo" o "agrario", su origen se remite a la divulgación de la resolución 125 que aplicaba retenciones móviles a la exportación de un conjunto de productos agropecuarios con alta rentabilidad en el mercado externo. ${ }^{2}$

Este conflicto que por 120 días $^{3}$ tuvo en vilo al país estuvo atravesado por múltiples contradicciones, discrepancias y confusiones promovidas por ambos sectores en pugna. De hecho ni representó a todo el sector agrario, ni enarboló una problemática universal para la mayoría de los que viven para y del campo (argumento de los referentes del sector agrario) ni tampoco estas retenciones fueron pensadas para frenar la "sojización"4del país ni para atender las necesidades de los más desposeídos o mejorar la distribución de la renta (argumento del gobierno). Por el contrario, el análisis de las distintas posturas y acciones de los sectores en pugna, da cuenta que el aumento sustantivo del precio de los "commodities" en el mercado externo estaba generando una renta extraordinaria (potenciada por las excepcionales condiciones productivas de Argentina, especialmente en las zonas ecológicamente favorecidas). La disputa por la apropiación de esta renta extraordinaria y su utilización desembocó en un enfrentamiento al interior de los sectores dominantes. Y, por ello, este conflicto adquirió una relevancia impensada, mientras otra serie de disputas que suceden en diversas áreas rurales del país, no se relevan, ni se difunden, ni se reconocen. Se trata de conflictos asociados a problemáticas de los sectores más desposeídos y que consisten en diferentes modos de resistencias al modelo hegemónico, por ejemplo contra los procesos de sojización y deforestación.

En este trabajo, a partir de estudios de caso, aplicando metodologías cualitativas y desde una perspectiva analítica que visualiza los conflictos como expresiones de luchas de poder por los recursos del territorio, nos proponemos mostrar las contradicciones y consecuencias territoriales de conflictos asociados tanto con disputas por el poder hegemónico como los vinculados con resistencias al modelo de desarrollo dominante y excluyente.

En la primera parte, realizamos una caracterización del conflicto del "campo", teniendo en cuenta los actores enfrentados y los argumentos que sustentaron las distintas posturas en pugna, identificando los intereses respectivos.

En la segunda y tercera parte, analizamos las consecuencias territoriales que ha tenido el modelo neoliberal, y específicamente el modelo agropecuario dominante, limitando el desarrollo inclusivo de la mayoría de los actores presentes en el "campo". Además exponemos la enorme diversidad presente en el medio agrario argentino. Todo ello nos lleva a cuestionar la representatividad de quienes intentaron postularse como defensores de los intereses del "campo" en su totalidad.

En la cuarta parte, nos centramos en el análisis de los otros conflictos que se suceden en ese mismo "campo" que se pretende uniforme y que no tienen, ni tuvieron, la misma repercusión política y mediática. Ya que se trata de resistencias al modelo productivo dominante y en expansión en las últimas décadas. Allí, partiendo de una breve exposición del marco analítico, focalizamos el análisis en algunos resultados sobre dos estudios de caso. En la última parte, presentamos algunas reflexiones sobre el análisis realizado. 
Conflictos territoriales em

ámbitos rurales de la Argentina actual, pp. 197 - 218

\section{Antecedentes y caracterización general del conflicto del "campo"}

Considerar al conflicto de marzo de 2008 como el conflicto del "campo" o "agrario" es el primer abuso terminológico, no casual. Ya que esta denominación conlleva a pensar que el "campo" es uno solo e indistinto y que no existen diferenciaciones sociales y sectoriales internas; 0 bien que las desigualdades internas son menores. Cuando en Argentina las asimetrías son cada vez mayores y la exclusión y expulsión de los productores y trabajadores aumenta. ${ }^{5}$ En realidad se trata de un eufemismo dirigido a lograr consenso y legitimidad y consecuentemente poder.

La importancia de este enfrentamiento radicó en que a partir de una demanda sectorial (ligada al agro) y autoproclamada "federalista" (como expresión de los intereses de las distintas provincias y de múltiples sectores sociales mancomunados -altos, medios y bajos) se puso en juego el poder político y económico entre diferentes propuestas dominantes. Fundamentalmente, una ligada a la expansión del monopolio exportador de los agronegocios, donde la oligarquía terrateniente tradicional, de histórica vertiente conservadora, tuvo un rol importante. Y la otra, asociada a otros importantes sectores monopólicos (industriales, mineros, petroleros, forestales, siderúrgicos, financieros e incluso agroindustriales -vitivinícolas, citrícolas-) muchos de los cuales en las últimas décadas han resultado beneficiarios de una amplia política de gasto público y subsidio por parte del Estado. Beneficios sólo posibles con recursos del Estado, en su mayor parte provenientes de las ganancias extraordinarias resultantes de un mercado de granos en expansión a nivel internacional, potenciado por las crecientes ventajas comparativas del sector agropecuario argentino.

En realidad, se trata de monopolios en muchos casos muy interconectados, que según las circunstancias tanto confluyen como se enfrentan en su relación con la sociedad, con el Estado, con la oligarquía terrateniente tradicional. Además, es fundamental tener en cuenta que los monopolios exportadores, los agronegocios en particular, los monopolios petroquímicos, de la información, del transporte y de servicios en general que operan en Argentina, son grupos corporativos de poder a nivel global y que en su pelea por expandirse y aumentar sus ganancias, promueven alianzas diversas, tanto con el Estado como con variados actores locales más o menos poderosos, dirigidas fundamentalmente a ubicarse frente al Estado como su interlocutor privilegiado. Así es como históricamente sucesivos gobiernos nacionales se han vinculado con sectores empresariales según fueran sus intereses políticos y económicos (frecuentemente no asociados al interés mayoritario nacional).

Precisamente, el enfrentamiento que se generó a partir de marzo de 2008 (que bajo otra forma aún continúa) fue de tal magnitud que fisuró la hegemonía política ejercida, sin discusión, desde 2002 hasta 2008, por quien fuera el entonces presidente Néstor Kirchner, seguido luego por la actual presidenta Cristina Fernández de Kirchner. ${ }^{6}$

En síntesis, esta pelea constituyó:

a) Una puja entre sectores monopólicos por la apropiación de la renta extraordinaria resultante de la combinación virtuosa entre precios en alza en el mercado internacional y alta productividad de la tierra en las zonas agropecuarias de Argentina.

b) Una contundente y extendida manifestación de protesta contra las retenciones móviles que habían sido instrumentadas por el gobierno, con corte de rutas y piquetes a lo largo de 3 meses. Su extensión temporal y geográfica afectó, en numerosos ámbitos locales, el abastecimiento de alimentos y otros productos. Espacialmente se concentraron en las zonas productoras de granos (pero no exclusivamente, porque otro tipo de productores se plegaron con sus propios reclamos -ver mapa 1 más adelante)

c) Una coalición de fuerzas no imaginada ni por los propios dirigentes del agro. Nos referimos al apoyo y participación de una variedad de actores que tomaron parte, de diferente modo, en las manifestaciones, piquetes y protestas y, de esta forma, avalaron las demandas de los sectores agrarios más conservadores. ${ }^{7}$ Asimismo, además de pequeños y medianos chacareros, trabajadores del campo, 
se destacó la presencia de actores urbanos. ${ }^{8}$ Muchos de ellos veían peligrar sus ingresos si se afectaba la renta de la producción sojera (como en el caso de los rentistas cuyos arrendatarios eran productores de soja). Otros eran pobladores urbanos, de sectores medios y altos, descontentos con la política del gobierno de los Kirchner en variados sentidos.

Entre los críticos al gobierno estaban tanto los que provenían de un perfil progresista, que acusaban al gobierno de ausencia de auténticas políticas de equidad, de redistribución de ingresos y de manejo poco transparente de los recursos, como los que lo criticaban desde posturas de derecha por su estilo populista, por la falta de institucionalidad, por la corrupción y por incentivar las políticas de derechos humanos y los juicios a los represores. En general, en temas vinculados con la escasa transparencia de las acciones del gobierno y el manejo discrecional de las instituciones había coincidencia entre unos y otros. Es decir, se constituyó en una protesta que al aunar sectores muy diferentes en su postura y expresión política, condujo a hilvanar un discurso crítico que pulsó todos los aspectos de la política pública. Por ello desembocó en un gran debilitamiento del gobierno, que de distinto modo, se mantiene hasta el presente y no logró avanzar más porque la oposición no puede conformar una unidad. No se trata en realidad de una oposición ideológicamente próxima entre sí. Por el contrario, son muchas sus diferencias, algunas imposibles de compatibilizar. Por cierto hay grupos opositores para los que es más factible aproximarse al gobierno que a determinados referentes de la oposición.

d) La utilización de un discurso opositor (con fuerte sustento en la ideología de los sectores tradicionalmente conservadores de la Argentina) fue aprovechado por el gobierno para hablar de desestabilización y para colocarse políticamente en la vereda opuesta de los intereses de la "nueva derecha conservadora". Desde el gobierno y sus aliados se divulgó esta puja como si se tratara de una disputa entre modelos de desarrollo, uno conservador y otro progresista.

Por lo tanto, creemos que faltó responsabilidad institucional en los dirigentes en general (salvo puntuales excepciones). Porque esta disputa llevó a un enfrentamiento extremo que dejó graves secuelas para el funcionamiento del Estado, afectó la gobernalidad y sus consecuencias aún persisten a más de un año de su inicio. En particular, en lo que concierne al conflicto "del campo", las partes intervinientes no dijeron todo lo que saben y conocen sobre cuestiones centrales que hacen a la problemática agropecuaria. $Y$ en ambos casos se ocultó que este conflicto, en realidad, estaba expresando una compleja disputa de poder entre sectores hegemónicos, en la que estaba en juego una trama de intereses opuestos, peleando la hegemonía de distintos modelos de acumulación capitalista.

\section{Las consecuencias territoriales de las transformaciones estructurales neoliberales}

La problemática del sector agropecuario, para ser comprendida adecuadamente, requiere reconocer las profundas transformaciones socioeconómicas operadas en todo el ámbito nacional, como consecuencia de las políticas de liberalización, desregulación y privatizaciones iniciadas en los años '90. Porque éstas implicaron un cambio del orden territorial, institucional, económico y social que explica el trasfondo de las principales restricciones que condicionan el futuro nacional, en términos de mejores oportunidades sociales, culturales y económicas para la mayoría de la población. De esto no se habla.

Distintas fotografías pueden mostrarnos al país actual. Algunas, reflejarán el abandono espacial y poblacional resultante de la desaparición, en los años de la década de 1990, de las líneas ferroviarias de larga distancia, para el traslado de pasajeros y de carga. Se trata de las vías que unían los puntos más lejanos del territorio nacional, transportando (a un costo subsidiado) los insumos y la producción desde y hasta distintos ámbitos locales de las economías regionales argentinas. Otras imágenes nos mostrarán un moderno y privatizado ferrocarril, como el nuevo Central Argentino (también subsidiado) destinado al transporte de carga. Este 
Conflictos territoriales em

ámbitos rurales de la Argentina actual, pp. $197-218$

recorre el circuito pampeano más productivo, entre Buenos Aires y Santa Fe, traslada al puerto de Rosario y de Buenos Aires la producción agropecuaria de las mayores empresas agroindustriales y comercializadoras de granos. Aceitera General Deheza ${ }^{9}$ es, no casualmente, quien gestiona y administra este ferrocarril. Este es un ejemplo del proceso de "corporativización del territorio" (Santos 2009 [1996]: 336) que se produce como consecuencia de inversiones públicas diferenciales (en este caso de manera indirecta desligándose el Estado de la prestación de un servicio básico y subsidiando aquellas líneas ferroviarias "rentables" para el capital privado).

Este contexto no puede menos que llevar a agudas transformaciones territoriales, de un amplísimo espectro. Por citar solo un ejemplo: ya no es más el ferrocarril el medio para trasladar la mayor parte de la producción nacional e internacional, ahora son enormes camiones que circulan por rutas nacionales y provinciales, también privatizadas, cuya densidad de transporte ha modificado las formas de movilidad de la población, los asentamientos a la vera de su recorrido, así como también las condiciones de seguridad en el traslado de la población en general.

Asimismo otras imágenes, más esparcidas por el espacio, nos indicarán la pérdida de cerca de 90.000 productores agropecuarios entre 1988 y 2002, en su mayor parte pequeños. Familias enteras debieron dejar su explotación agropecuaria, porque su actividad se tornó inviable en el contexto de la convertibilidad ( $y$ esto a pesar que muchos de ellos estaban localizados en la rica zona pampeana, hoy en franca expansión productiva). ${ }^{10}$ Del mismo modo, aparecerán distorsionadas las fotografías que ilustraban la presencia de cientos de pequeños pueblos. Ya que su vida se truncó junto con la de los antiguos ferrocarriles que pasaban a su vera, o con la de las empresas públicas luego privatizadas (como sucedió en el caso de YPF, en Pico Truncado, Santa Cruz o en Tartagal, Salta).

Junto con los recorridos suspendidos - las líneas y ramales levantados, o las empresas y servicios clausurados, miles de personas perdieron sus trabajos y debieron emigrar con sus familias completas o desmembradas. En el presente, el reverso de esta imagen es el resurgimiento de otros pueblos en la zona de producción agrícola de "commodities" (tanto del área pampeana como extrapampeana). Conjuntos poblacionales que se ven favorecidos por la fuerte dinámica económica y comercial impresa por el boom agropecuario (que movilizó hacia estos lugares a inversores, contratistas, comercios y servicios de maquinaria e insumos agropecuarios, además de otros comercios y servicios indirectamente relacionados).

El impresionante crecimiento productivo y alta rentabilidad nacional de la soja no puede analizarse fuera de los procesos de transformación a escala global. Los años '90 consolidaron transformaciones tecnológicas que implicaron mayor flexibilidad y ubicuidad para la localización de las actividades productivas en general (tanto de industrias como de agroindustrias). La producción de granos se expandió más allá de la pampa húmeda, resultado no sólo del corrimiento del ciclo húmedo sino también de nuevas oportunidades en tecnología e insumos (avances científicos en genética, en sistemas de comunicación e información).

Asimismo, es importante tener en cuenta que varias cuestiones que se suceden a nivel nacional e internacional, asociadas a la expansión de la soja, conllevan riesgos mayores para los productores pequeños y medianos que las que suponen las propias retenciones que hoy se cuestionan. A saber:

a. El contexto de concentración y extranjerización de la producción agropecuaria nacional (favorecido por las privatizaciones y las desregulaciones) no parece haberse detenido luego de la devaluación y, consecuentemente, tampoco la expulsión de los productores pequeños y medianos.

b. La fuerte expansión del mercado de soja tiene mucho que ver con varias cuestiones económicas, financieras y sociopolíticas. Por ejemplo, una de ellas es la especulación financiera que se viene produciendo en los grandes mercados mundiales a través del alza de los precios de los commodities, entre los cuales la soja ejerce un rol dominante. Otra, es el giro político y económico de China a favor del mercado capitalista. China 
se constituyó en el principal demandante y comprador mundial de soja (también de Argentina). Representa un volumen de demanda desconocido hasta el presente y de gran interés para el capital transnacional, que irá aumentando sus coacciones para obtener mayor disponibilidad de tierra apta. Lo cual terminará promoviendo nuevas formas de expulsión de los ocupantes y pequeños propietarios de tierras.

c. La promoción de un nuevo orden energético mundial basado en los agrocombustibles, impulsado desde Estados Unidos y Brasil, constituye otro elemento que presiona por más tierra cultivable. Además, representa una nueva amenaza a la seguridad alimentaria de la población mundial, porque los agrocombustibles ocupan el espacio de producción de alimentos y los desplazan, cuando es posible, a zonas marginales.

Toda esta realidad viene operando en un marco de liberalización jurídica que favoreció la internacionalización de los patrones mundiales de consumo y producción, además de la concentración económica. Evidentemente se trata de un modelo a escala mundial, totalmente indiferente a los costos ecológicos y sociales que implica. Tanto no tiene en cuenta la exclusión y emigración de la población rural de menor capacidad económica como tampoco las consecuencias medioambientales de la monoproducción de soja (o cualquier otro agrocombustible).

\section{La diversidad del campo argentino}

Tanto las geografías que podríamos reconocer como "campo" en Argentina, como la población al mismo ligada (sea directa o indirectamente) están lejos de expresar alguna singularidad, alguna característica de identificación común. Más aún, incluso el campo pampeano, privilegiado en la imagen de Argentina en el mundo, por su alto rendimiento y rentabilidad diferencial, tampoco puede reducirse a una visión unívoca, socialmente indiferenciada.

Combinaciones múltiples de población, etnias, cultura, historia, recursos naturales, medio ambiente, sistemas productivos, tecnologías, organizaciones, distancias, calendario agrícola, se dan y suceden por todo el territorio nacional, conformando una amplísima variedad de economías regionales y formas productivas agropecuarias, muy diferenciadas entre sí. Sólo por citar algún ejemplo: no son lo mismo los medianos y grandes productores de tomate del departamento de Orán en Salta (con un producto primicia de primera calidad), que los horticultores de origen mestizo o aborigen del Valle Calchaquí, también en Salta, ó los bolivianos del conurbano bonaerense. Todos producen tomate, pero muy distinto y de muy diferente manera; no llega ni en tiempo, ni en forma, ni en calidad similar a los mercados, ni su rendimiento y su costo reditúa igual en sus "bolsillos". Si se necesitara diseñar una política nacional de promoción de la producción de tomate, muy distintas deberían ser sus especificidades según tipo de productores $y$ zonas productoras. Porque una política universal, o sea para todos por igual, evidentemente implicaría consecuencias e impactos diferenciales entre actores y ámbitos espaciales (incluso inversos a los buscados). En este caso lo que se requeriría es una política nacional diferenciada según especificidades locales.

Del mismo modo, puede pensarse el caso de los que producen soja, principales afectados por las retenciones móviles, disparadoras del conflicto. Entre ellos, tanto están los localizados en la zona de mayor productividad de la pampa húmeda ${ }^{11}$ como los que se asientan en áreas marginales del chaco semiárido, en las provincias de Salta, Chaco y Santiago del Estero. Por ello ocurre que, en un mismo ámbito espacial (departamento, municipio) aparecen medianos y grandes arrendatarios y propietarios, gestionando explotaciones de $3.000,5.000$ ó 10.000 ha, junto a otros cuyos predios no superan las 100 ó 200 ha. Es así como productores pequeños, medianos y/o grandes conviven con muy disímiles rentabilidades, costos y acceso a los mercados.

Asimismo, tampoco el campo es ya el que hemos conocido y que nos han enseñado en las escuelas y universidades. En la década de 1990 se consolidan nuevas prácticas y formas productivas que conforman una realidad totalmente diferente a la de períodos anteriores. 
Conflictos territoriales em

ámbitos rurales de la Argentina actual, pp. $197-218$

En el presente, entendemos más el "boom" agrícola si analizamos la concentración de la producción que la concentración en la propiedad de la tierra. Porque, la mayor parte de la producción granaria proviene de empresas, pools, fondos de inversión, fideicomisos financieros, que producen a través del arrendamiento de grandes extensiones de tierra, bajo la forma de contrato por cosecha; y que tienen un rol más significativo en la producción que los grandes propietarios, que los terratenientes, que los latifundistas, que la antigua oligarquía pampeana.

Aparecen entonces nuevos actores que prefieren arrendar (y no comprar) buscando acceder a la mayor cantidad de campos disponibles en diferentes provincias para luego dedicarse al monocultivo de soja (dada su altísima rentabilidad en el mercado externo). ${ }^{12}$ Estos: ¿a quiénes arriendan? A ex productores que, por el contrario, prefieren no seguir explotando directamente sus campos, a causa de que experimentan restricciones de capital, tierra y otros recursos. Y, en cambio, obtienen mayores ingresos arrendándolos. Además, el precio por hectárea del arriendo viene siendo significativo para los pequeños propietarios de tierras aptas, especialmente para los localizados en la pampa húmeda. ${ }^{13}$

Sin embargo, este modelo productivo, basado en la producción por contrato, por cosecha, hace un uso muy intensivo de la tierra, con poca rotación y diversificación, y ello conlleva a la depredación del suelo por la escasa reposición de nutrientes. Este deterioro de la tierra, de todos modos, no afecta a estos nuevos arrendatarios, ya que ellos tienen la posibilidad de seguir produciendo desplazándose hacia otras tierras. En cambio sí afecta al propietario, que tendrá que esperar años para que se recuperen sus suelos (si se recuperan) y, por supuesto, que en definitiva compromete el futuro productivo de toda la Argentina.

Se trata, asimismo, de una forma de producción que permanentemente presiona para sumar nuevas tierras y ponerlas en producción bajo esta forma productiva. Y por ello incentiva los procesos de deforestación con el consiguiente avance de la frontera agropecuaria, expansión del uso de agroquímicos y expulsión de pequeños productores y aborígenes de los predios que vienen ocupando desde décadas atrás. Numerosos grupos ambientalistas, campesinos e indígenas, han denunciado estas acciones, sin embargo es escasa su difusión en los medios. Lo cual se explica porque estas denuncias comprometen a grandes intereses económicos.

$Y$ en este contexto, no podemos dejar de mencionar que también hay pequeños productores localizados en zonas extrapampeanas y, aún, en la pampa húmeda, que llevan a cabo otro modelo productivo. Son los que, aún produciendo soja, no practican el monocultivo en su parcela, porque la tierra es el sostén de su trabajo o de su subsistencia y deben cuidarla para que no se agote. Por ello, destinan parte de su superficie a otras producciones (como horticultura o ganadería). Entre éstos encontramos tanto pequeños productores familiares cuyo objetivo es insertarse y sostenerse competitivamente dentro del mercado, como los que centralmente se abocan a garantizar la alimentación familiar o los que persiguen objetivos de más largo alcance como la soberanía alimentaria.

Hay en todos ellos, otra lógica en la toma de decisiones, en la que no domina el criterio único de mayor rentabilidad. Son productores que buscan conservar ambientalmente su predio, que resisten su desalojo, que aprecian la vida rural, que la valorizan frente a la potencial emigración a los suburbios de las ciudades, a la marginalidad.

En la mayoría de las actividades agropecuarias, por lo tanto, operan productores con diferentes capacidades y poder, con intereses muy disímiles y, frecuentemente, enfrentados (explícita o tácitamente) en el uso y disponibilidad de los recursos que potencialmente pueden compartir (tierra, mercados, mano de obra, capital, información, subsidios). Porque el acceso y control de esos recursos confiere poder. Y este poder (diferencial según los actores) está en disputa en los espacios productivos. Así fue y ha sido siempre a lo largo de toda la historia nacional y mundial.

Entonces, no es posible pensar seriamente que exista confluencia de intereses 
dentro del conjunto de productores que participaron o que apoyaron las medidas de fuerza que se tomaron en el marco del "conflicto del campo". Porque las asimetrías sociales y económicas eran y son notorias, tanto dentro de una determinada actividad productiva (como en el caso de la soja) o entre varias de ellas (soja, carne, lácteos).

Por ello, la conjunción de intereses tan diversos, sólo puede ser coyuntural, sin posibilidad de sostenerse en el largo plazo. De aquí que cualquier resolución final, necesariamente va a terminar beneficiando diferencialmente a unos respecto a otros, o sólo a algún sector de todo este conjunto. ${ }^{14}$ Mucho menos podemos pensar que quienes se pusieron al frente del conflicto ${ }^{15}$, representaban los intereses de la mayoría de los productores. Por el contrario, formaban parte, sostenían y fomentaban un modelo productivo tendiente a desplazar a numerosos pequeños productores del agro argentino.

\section{Los "otros" conflictos por los recursos territoriales}

\begin{abstract}
Más allá del conflicto que hemos descripto entre las organizaciones de representación del sector exportador de alimentos básicos y el Gobierno Nacional por la aplicación de retenciones móviles, importa rescatar la existencia de muchos otros conflictos que se vienen sucediendo en diversas áreas rurales del país y que expresan formas de resistencia de la población local frente a un modelo económico que tiende a acentuar las desigualdades existentes en los territorios.
\end{abstract}

Durante el conflicto "del campo", muchos otros sectores sociales, en general de economías extrapampeanas, pero no únicamente, se preguntaban: ¿por qué es éste el conflicto que domina la escena nacional?, ¿por qué no trascienden los cientos de conflictos que se suceden en relación a la expoliación y extranjerización de recursos naturales (como el agua, la tierra, los minerales, los bosques)?

Son los que en nuestra investigación denominamos conflictos territoriales. Es decir, disputas que se hacen públicas entre distintos actores por recursos o condiciones de producción y seguridad ambiental. En general este tipo de conflicto enfrenta a los sectores subalternos (pequeños productores, comunidades indígenas) con los vinculados al poder hegemónico en disputas, en muchos casos históricas, por la tierra, el agua, la minería, la biodiversidad, la infraestructura.

Sin embargo, la mayoría de los "conflictos territoriales" no han tenido, ni tienen la repercusión, ni el poder de convocatoria de sectores medios urbanos que tuvo el "del campo". Son poco conocidos, no son "mediáticos", porque afectan intereses económicos de sectores poderosos del país y del extranjero. Y, su mayor difusión, podría conducir a una ampliación de la protesta, a su generalización a nivel nacional, dada la gran cantidad de situaciones similares que se reproducen a lo largo de la geografía argentina. Lo cual pondría en riesgo o crearía dificultades a la consecución del proceso de concentración y de acumulación capitalista que se viene operando en todos estos ámbitos y que es causa de las disputas en cuestión.

Conflictos de estas características son particularmente numerosos en las provincias del norte (ver mapa 1). ${ }^{16}$ Lo cual está asociado a que allí predominan pequeños productores familiares y población aborigen. Pero también se vincula con mayores porcentajes de tenencia precaria de la tierra y de pobreza rural. Asimismo, es en estas provincias donde en las últimas décadas, y con mayor intensidad desde el año 2002, se viene acentuando la expansión de actividades económicas gestionadas por grandes empresas, altamente intensivas en capital. Estas, en su accionar, presionan de diversa forma y en múltiples aspectos a los productores familiares y a las comunidades indígenas. Y éstos terminan siendo desplazados de sus tierras y más marginados aún de lo que ya estaban previamente. El caso de la expansión de la producción de soja en las provincias de Chaco, Santiago del Estero y Salta es un ejemplo paradigmático de esta situación (Slutzky, 2005). 
Conflictos territoriales em

Mapa 1: Conflictos en áreas rurales de Argentina, 2007 y 2008.

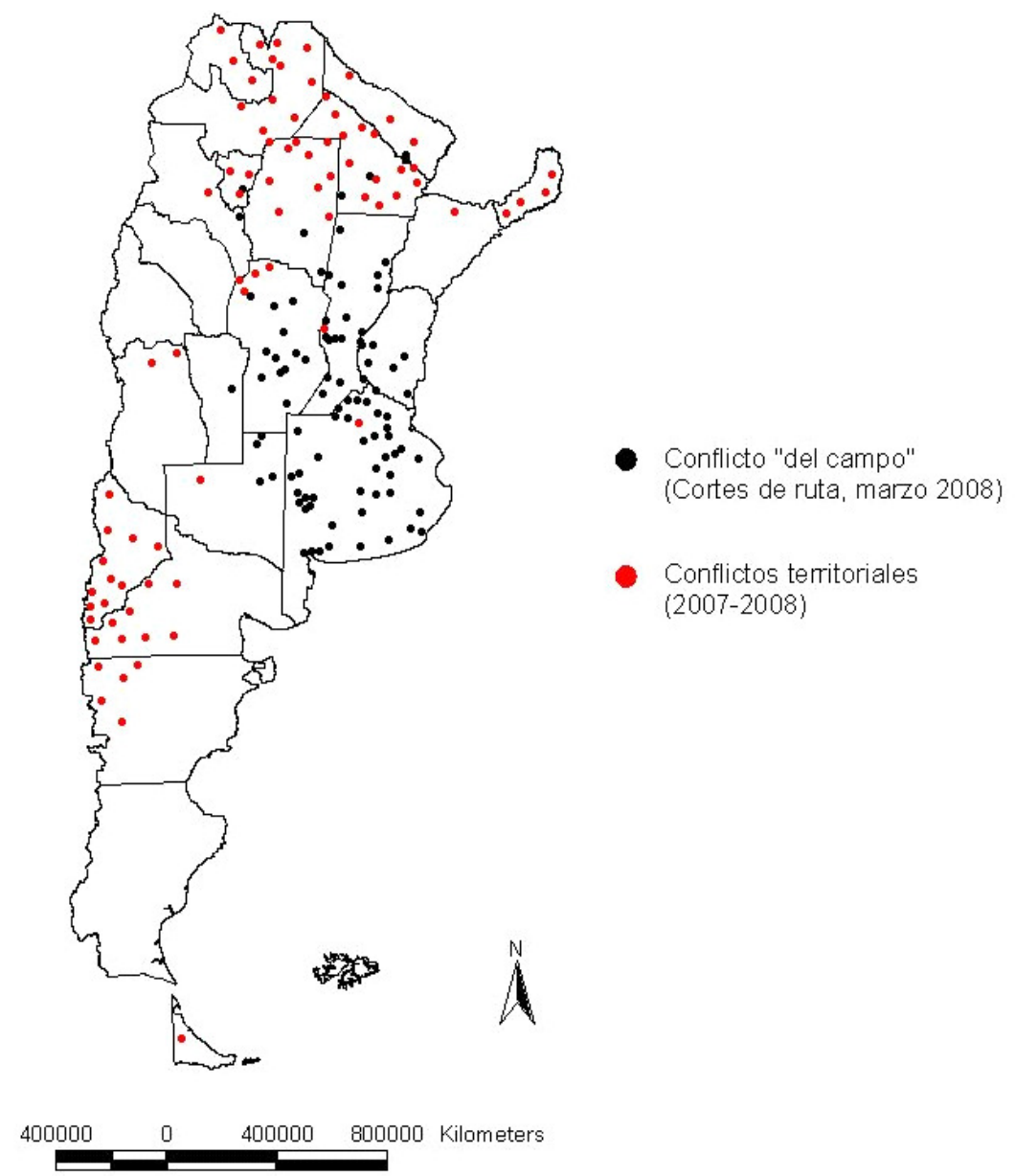

Fuente: Domínguez, Diego (2010) y Diario La Nación de los días 17, 19, 21, 23 y 31 de marzo de 2008.

Pero hay también otras actividades económicas que están ejerciendo presiones similares, como sucede con la minería, el turismo, la forestación. En muchos casos estas actividades se ven dinamizadas por capitales extranjeros que aprovechan las oportunidades de inversión y los subsidios que otorga el Estado nacional o los Estados provinciales en sectores de alta rentabilidad, bajo la consigna de que ese tipo de inversiones son una oportunidad para el crecimiento nacional $y$, consecuentemente, una real contribución para el desarrollo (Prf. Manzanal, 2010: 26).

En nuestro proyecto de investigación (Territorio y poder en la globalización: estudios de caso) venimos relevando y analizando distintos tipos de conflictos territoriales en las provincias de Salta (noroeste) y Misiones (nordeste) que 
refieren a lo anterior. Consideramos que cuando un conflicto se hace público (más o menos explícitamente) y pone en juego intereses contradictorios, las relaciones de poder que operan en el territorio se hacen más evidentes. $Y$ por ello también surgen más nítidamente los elementos explicativos de los fenómenos económicos y sociales determinantes del desarrollo y de las desigualdades consecuentes. De aquí que en esta investigación focalizamos el análisis en experiencias puntuales y acotadas que evidencian una disputa por el poder territorial. Dichas experiencias expresan las luchas de los actores que se enfrentan u oponen al marco institucional dominante, aquél que perpetúa las relaciones sociales desiguales.

Las distintas manifestaciones de conflictos y movimientos sociales que se vienen experimentando en Argentina y otros países de América Latina en los últimos años ${ }^{17}$ cuestionan las formas históricas de institucionalización de los conflictos estructurales y proponen otras formas de negociación de los mismos, apuntando a un cambio en las relaciones de poder.

Nuestro punto de partida para este tipo de indagaciones ha sido la incorporación del análisis institucional y territorial desde una mirada crítica. En relación con las instituciones, esto significa "alejarse de toda sacralización de leyes y normativas impuestas por la sociedad", debido a que "partimos de la premisa que, en el contexto de la globalización y la modernidad, la adscripción y cumplimiento sin cuestionamientos del conjunto de normas y reglamentaciones existentes, conduce a la consecución de una sociedad desigual" (Manzanal, 2007: 28). En este sentido, seguimos a Bourdieu (2006) quien destaca el rol de las instituciones en la reproducción del orden social y en la permanencia de las relaciones de dominación. Estas operan a través de relaciones de poder y de dependencia que no se establecen "directamente entre las personas" sino que se "objetivan" entre y a partir de las "instituciones". Los títulos, las leyes, las normas, constituyen una "legitimación del orden establecido" y logran que las relaciones de dominación permanezcan invisibilizadas, ocultas, garantizando de este modo la reproducción del orden social y su permanencia (Bourdieu. 2006: 57 y ss.).

En cuanto al territorio, partimos de una conceptualización que lo define como un ámbito de disputa, como un "espacio definido y delimitado por y a partir de relaciones de poder" (Lopes de Souza, 1995: 78). Considerando desde el "poder más material de las relaciones económico-políticas, al poder más simbólico de las relaciones de orden más estrechamente cultural" (Haesbaert, 2006 [2004]: 79).

El territorio aparece desde esta perspectiva como un producto del accionar conjunto de los actores que lo habitan o ejercen influencia sobre él. Y este accionar de los actores en su relación con el espacio puede representar: (a) un proceso de apropiación, más simbólico, cargado de las marcas de lo vivido, de valor de uso y (b) un proceso de dominación políticoeconómica, relación más concreta, funcional, vinculada al valor de cambio de los espacios (Haesbaert, ibid: 93-96). Por lo que el territorio "en cuanto relación de dominación y apropiación sociedad-espacio, se desdobla a lo largo de un continuum que va de la dominación políticoeconómica más 'concreta' y 'funcional' a la apropiación más subjetiva y/o 'cultural-simbólica" (ibid 95-96). Y aunque no puedan separarse completamente esas esferas "cada grupo social, clase, institución puede 'territorializarse' a través de procesos de carácter más funcional (económico-político) o más simbólico (políticocultural) en la relación que desenvuelven con 'sus' espacios, dependiendo de la dinámica de poder y de las estrategias que están en juego" (ibid: 96). Esos dos procesos suelen entrar en contradicción y conflicto, siendo generalmente la "dominación político-económica" la que se impone, reduciendo los espacios efectivamente "apropiados" (Prf. ibid). Esta distinción conceptual respecto de esas múltiples dimensiones del poder que interactúan en la producción del territorio, nos permite dar cuenta de la confrontación evidente o latente de intereses enfrentados por el control y uso de recursos del territorio que se visualizan en distintos lugares del país.

Asimismo debemos considerar el doble carácter del territorio: (a) como soporte de 
Conflictos territoriales em

ámbitos rurales de la Argentina actual, pp. $197-218$

redes que trasladan las reglas y normas utilitarias desde el punto de vista de los actores hegemónicos y al mismo tiempo como (b) espacio que es sede de acciones localmente constituidas, que amplían la cohesión de la sociedad civil al servicio del interés colectivo (Santos, 258-259), pudiendo conformarse a la vez como "espacio de resistencia social".

Entendemos, a partir de todo lo anterior, la producción del territorio como resultante de las prácticas socioespaciales de apropiación y dominación de objetos, recursos, bienes y de imposición de símbolos, creencias, valores, que distintos actores (locales y extralocales) ejercen sobre un ámbito espacial de referencia, según las cuotas diferenciales de poder que los actores detentan y según las estrategias de desarrollo que están en juego. Estas diversas prácticas van a dar cuenta del tipo de espacioterritorio construido y de las particulares formas que asumirá el desarrollo y la desigualdad social en el mismo (Manzanal, 2007: 33).

Este marco analítico ${ }^{18}$ ha sido útil para analizar un conjunto de situaciones de despojo y enfrentamiento con poca prensa y limitada difusión pública que se vienen experimentando en distintos ámbitos rurales de la Argentina. Precisamente, cuando nos adentramos en su problemática aparecieron expresados con mucha definición los intereses en pugna (véanse diferentes casos investigados en Manzanal y Villarreal -Org.- 2010). De acuerdo a lo analizado en ítems anteriores, queda claro que el conocido como "conflicto del campo o agrario" no se encuadra en estos cánones.

Una primera parte de la investigación que llevamos adelante, consistió en un relevamiento general de los diversos conflictos que se vienen desarrollando en ambas provincias desde los inicios de la década de 1990, a partir de la revisión de fuentes periodísticas. La parte central de la investigación, por su parte, consiste en un estudio en profundidad de tres de esos casos. $^{19}$

Del análisis de la información periodística relevada y sistematizada, observamos que numerosos y diversos conflictos tienen lugar en estas provincias en las últimas dos décadas (Ataide y González, 2009). ${ }^{20}$ En relación con los ejes problemáticos en torno a los cuales se fue organizando la demanda de los actores, hemos podido observar que los mismos se vinculan con tres cuestiones que en muchos casos aparecen combinadas: ambiente, obras de infraestructura y tierra, siendo los principales actores demandantes pequeños productores, comunidades indígenas y organizaciones de distinto tipo (ambientalistas, religiosas, sindicales, de apoyo a pequeños productores y aborígenes, etc).

En lo que sigue haremos mención resumidamente a los conflictos relevados en Salta, con especial mención a aquellos que tienen lugar en los Valles Calchaquíes, para luego centrarnos de manera más detallada en el caso de Misiones $y$, en particular, en el conflicto por la tierra, objeto de nuestro estudio. Nos interesa analizar más en profundidad este caso porque hubo un intento de resolución institucionalizado (una ley de expropiación de las tierras dictada por el gobierno provincial). Lo cual da cuenta de su importancia para el entretejido del poder local.

\section{Los conflictos territoriales en la provincia de Salta}

La mayor parte de los conflictos relevados en esta provincia aparecen asociados al medio ambiente. Se trata de reclamos cuyo motivo principal es la alteración o modificación del "ambiente" en un territorio, sea por la realización de una gran obra de infraestructura o por el desarrollo de alguna actividad productiva (ibid: 246).

En Salta, estos reclamos están vinculados con los desmontes que se están produciendo en el nordeste de la provincia como consecuencia de la expansión de la producción de soja. En otros casos, están asociados con la minería y con la construcción de obras de infraestructura de distinta magnitud. ${ }^{21}$

En los Valles Calchaquíes, por ejemplo, tienen lugar conflictos vinculados con estos dos últimos aspectos. Uno de ellos consiste en una prolongada disputa por el uso del agua de riego, un recurso escaso en la cuenca del río Calchaquí. En efecto, ya durante la época colonial, la 
apropiación de este recurso dio origen a una estructura de utilización y propiedad del agua considerablemente desigual, que ha sido legitimada a lo largo del tiempo por los "usos y costumbres", pero también por regulaciones, códigos y leyes (Manzanal et. al 2010). Se trata en este sentido de un conflicto histórico que enfrenta a los grandes productores situados aguas arriba del río, con los pequeños productores aguas abajo (en general, en ambos casos se dedican a la producción de pimiento para pimentón). La disputa se origina porque los grandes productores, para aumentar su producción, intentan tomar la mayor cantidad de agua posible, sin respetar el sistema de turnos establecidos para que el agua llegue a los pequeños productores, quienes se ven altamente perjudicados por este accionar (Villarreal, 2010: 189).

El Estado, por su parte, ha tenido un rol importante en la gestión dentro de la cuenca, en particular desde principios del siglo XX, a través de la realización de obras de infraestructura y de distinto tipo de regulaciones. Sin embargo, a partir de las reformas del Estado iniciadas en la década de 1990 y con el consecuente desmantelamiento de la institución estatal encargada de regular el manejo del agua, ${ }^{22}$ las expresiones de conflicto se tornaron más visibles, incluso en algunos casos violentas, mostrando claramente los diferenciales de poder existentes entre los grandes y los pequeños productores (ibid: 191). Lo que sucedió fue que la regulación del agua quedó en manos de los propios usuarios -organizados en Consorcios de Riego- y esto potenció la inequidad presente en el territorio. Ya que las posibilidades para administrar eficientemente estos consorcios difieren según capacidades económicas, culturales, políticas de quienes están a su cargo: no es lo mismo encarar esta gestión para los grandes que para los productores chicos. Además del hecho que los grandes productores, ante la ausencia de control, desconocen los derechos de los pequeños productores, acaparando una mayor cantidad de agua que la que les corresponde.

Las instituciones que legislan el uso del agua, instauradas por leyes y reglamentaciones desde la conformación misma del Estado provincial, tendieron a mantener las relaciones de dominación históricas, legitimando la distribución desigual de agua e interviniendo en los conflictos con el fin de evitar su recrudecimiento, pero sin modificar dicha distribución desigual (Prf. Manzanal et al, 2010).

El otro conflicto presente en los Valles Calchaquíes surgió en el año 2006 a partir del anuncio, por parte del Gobierno Nacional, de la reapertura de una mina de uranio en el departamento de San Carlos. Lo cual se da en un marco de activa promoción de la minería en la provincia, cuyo antecedente es la política nacional de la década de 1990 orientada a impulsar la minería a gran escala en el país. ${ }^{23}$

Lo anterior conlleva, en el caso de San Carlos, a la resistencia de sectores de la población local a la reapertura de la mina, bajo "la convicción de que el carácter radioactivo del uranio y la gran cantidad de agua utilizada en la explotación traerán aparejadas graves consecuencias para la salud y la economía regional, basada principalmente en la producción agropecuaria y la actividad turística" (Bonzi, 2010: 197).

El incremento significativo de las inversiones en la minería metalífera en el área de estudio dio inicio a diversos ciclos de protesta y al surgimiento de organizaciones que reunían a distintos actores del ámbito local, desde pequeños productores y comunidades indígenas, hasta docentes, artesanos, profesionales en general. Estos últimos en particular, provenientes de distintas áreas urbanas del país, fueron quienes promovieron la conformación de las organizaciones que encauzaron las demandas en contra de la minería (ibid: 206). Paulatinamente, el rechazo a la minería fue extendiéndose, generando la conformación de otras organizaciones en pueblos cercanos, a las que se sumaron otros sectores de la población local, así como las comunidades indígenas, con una participación activa en las protestas.

El conflicto desatado en torno a la mina Don Otto en San Carlos, expresa el posicionamiento de la población local en contra de un modelo de desarrollo considerado "insensible". Frente a esta situación, el Estado, principal promotor de la minería en el país en general y en esta zona en particular, trató por 
Conflictos territoriales em

ámbitos rurales de la Argentina actual, pp. $197-218$

distintos medios (en particular diversos procedimientos discursivos) de deslegitimar el accionar organizado de la población local (ibid: $214)^{24}$.

\section{Los conflictos territoriales en la provincia de Misiones}

En el caso de la provincia de Misiones también observamos el surgimiento de variados conflictos territoriales desde la década de 1990. Los conflictos ambientales son aquí manifestaciones de rechazo a la construcción de represas (o la elevación del nivel de los embalses) para la generación de energía eléctrica.

De todos modos, la mayoría de los conflictos están vinculados con la tierra. Con excepción de un caso, ${ }^{25}$ todos ellos involucran a pequeños productores y comunidades aborígenes que exigen la regularización de la tenencia de sus tierras o la restitución de territorios aborígenes ancestrales.

Uno de los conflictos por la tierra más importante tiene lugar en el nordeste de la provincia de Misiones. Ocupantes de tierras privadas (pequeños productores familiares orientados a la producción de alimentos y/o tabaco) se enfrentan con las empresas madereras dueñas de las tierras y el Estado provincial. ${ }^{26}$

Durante la década de 1990, la forestación cobró un fuerte impulso en Misiones, a causa de la creación de un marco jurídico propicio para la inversión y desarrollo de dicha actividad por parte del Estado nacional y provincial. ${ }^{27}$ Vinculado con la expansión de la forestación, se intensificó la concentración de la tierra, dominada por grandes empresas nacionales y transnacionales. ${ }^{28}$ Uno de los factores señalados por distintos autores como causa de la presión de los propietarios de grandes propiedades para desalojar a los ocupantes de las mismas es la revalorización de las tierras, asociada a la promoción y avance de la forestación. (Schiavoni, 2005; Kostlin, 2005). El incremento de la demanda de tierras para forestación elevó dos o tres veces su precio por ha. Y ello aumentó aún más el interés de los propietarios por disponer libremente de las mismas con el fin de: (i) reconvertirse, pasando de la extracción maderera nativa a la forestación, aprovechando al mismo tiempo los subsidios del Estado; y/o (ii) vender grandes extensiones aptas para forestar a inversores extranjeros y nacionales (Kostlin, 2005: 50).

El conflicto por la tierra se inició a principios de la década de 1990 con las primeras amenazas de desalojo. Este conflicto cobró notoriedad pública en el año 2000 (a diferencia de otros mencionados que han tenido un transcurrir poco conocido). La Pastoral Social de la Diócesis de Iguazú, junto a dos ONGs que se sumaron luego, fueron los actores que encaminaron el proceso de lucha, informando, asesorando y contribuyendo a la organización de los ocupantes.

La movilización evolucionó de la resistencia (a los desalojos), a reclamos orientados al logro de cambios estructurales ligados a la regularización de la tenencia de la tierra. También se configuraron otras demandas dirigidas a facilitar el asentamiento a largo plazo de los productores (con la construcción de viviendas e infraestructura vial, servicios de salud y educación y apoyo a emprendimientos productivos).

El accionar de los ocupantes y organizaciones de apoyo en pos de solucionar el conflicto llevó casi 15 años. Recién en noviembre de 2004 lograron la sanción de la Ley Provincial 4093, denominada Plan de Arraigo y Colonización. Esta ley contempla la expropiación por parte del Estado provincial de parte de las tierras en conflicto, una de las principales demandas de los ocupantes orientada a regularizar su situación en cuanto a la tenencia de la tierra en el área.

¿Pero cuánto se ha avanzado en esa materia? ¿En qué medida la situación de los ocupantes de tierras privadas ha mejorado a partir de la sanción de la Ley?

Nuestro análisis focaliza, justamente, en cómo se configura la trama de fuerzas en el territorio a partir de ese acontecimiento, qué perspectivas se perfilan en relación a la resolución del conflicto $y$, en términos más generales, en relación con el proceso de desarrollo en el área. ${ }^{29}$

En primer lugar, una serie de evidencias nos indican que, lejos de solucionarse, 
este conflicto permanece en un estado de latencia. Al respecto observamos:

a. Lentitud en la realización de cada uno de los pasos correspondientes a la implementación de la ley. Si bien se avanzó en la compra de las dos propiedades más pequeñas, en el caso de una de las propiedades más conflictivas aún no se realizaron las mensuras perimetrales.

b. Falta de acuerdo entre el Estado y los propietarios por el precio de las tasaciones y falta de decisión política para concretar, de todos modos, la expropiación. ${ }^{30}$ Los propietarios exigen que la revalorización de sus tierras sea a los precios de mercado del presente. Ello, en la mayoria de las situaciones, significaría la apropiación de ganancias extraordinarias. Es claramente el caso de una de las empresas que compró las tierras, con ocupantes, en un remate del Banco Nación en el año 2003, a un precio cinco veces menor al que exige ahora en esta nueva instancia. ${ }^{31}$

c. Incorporación de nuevos ocupantes. La Ley no consiguió detener el proceso de ocupación, que sigue su curso, en la medida que la demanda de tierras continúa muy alta. Si bien no hay datos que permitan estimar la magnitud de este proceso, distintos informantes coinciden en afirmar que nuevos ocupantes han ingresado a las tierras, así como otros se han ido. Esta situación plantea interrogantes respecto de las posibilidades de regularización de la tenencia, dada la alta movilidad territorial existente.

En segundo lugar, la sanción de la Ley tampoco logra solucionar el problema de "qué hacer con la tierra", en la medida en que no se construyen otras alternativas a la de la industria tabacalera para los pequeños productores. ${ }^{32}$ En efecto, el tabaco es el único cultivo de renta que los productores en situaciones irregulares de tenencia de la tierra pueden encarar, debido a que los otros cultivos de importancia en la provincia (yerba mate y té) por tratarse de perennes, requieren de cierta capitalización previa y condiciones de tenencia regulares (Schiavoni, 1995: 49). Y aquellas actividades productivas que en muy pequeña escala intentan abordar, no cuentan con el mismo apoyo que el Estado destina para fomentar la forestación u otras actividades consideradas básicas para "el desarrollo" de la provincia (como el turismo y el tabaco).

El fortalecimiento de la agricultura familiar a partir de la producción de alimentos, tal como pretenden los productores y las organizaciones de apoyo, se encuentra limitada, entre otras cuestiones, por la inexistencia de un mercado donde insertarse, que constituya una alternativa productiva viable y sustentable en el tiempo. Los pocos recursos que llegan a las organizaciones desde el Estado y las ONGs de manera dispersa y desarticulada, no contribuyen a consolidar ese proyecto.

Todas estas cuestiones expresan las profundas contradicciones que presenta el proceso de desarrollo en un ámbito rural marginal de la Argentina. Muy poco se conoce acerca de estas dinámicas, ejes de profundas desigualdades, constantemente exacerbadas por grandes capitales que presionan y avanzan sobre tierras y poblaciones que, sencillamente, no encajan en su modelo. Sin embargo, y al mismo tiempo, todos estos actores locales esperan ser partícipes de un proceso de desarrollo incluyente. Son voces que no llegan, ni repercuten en Buenos Aires, tampoco se realizan "cacerolazos" en su nombre.

\section{Reflexiones finales}

Los ejemplos que acabamos de exponer son cuestiones por demás conocidas por los dirigentes agropecuarios y sus bases, pero también por el gobierno y sus técnicos. Son hechos que marcan límites a las acciones conjuntas de las entidades agropecuarias y de los sectores sociales que representan. Ya que no hay política nacional, ni agropecuaria, que pueda incluirlos a todos, en tanto se trata de intereses opuestos en la práctica cotidiana, y donde se beneficia a uno se margina a otro.

Estas cuestiones refieren a problemas estructurales del país. Problemas que han sido dejados de lado sistemáticamente y que tienen su origen en la propia Organización Nacional (1880), cuando comenzó a consolidarse la hegemonía y el poder de la oligarquía terrateniente argentina. 
Conflictos territoriales em

ámbitos rurales de la Argentina actual, pp. $197-218$

La ausencia de un auténtico federalismo, la falta de renovación de la vieja y congelada ley de coparticipación de 1988, la debilidad del poder legislativo que admite que se gobierne con decretos extraordinarios de necesidad y urgencia, son temas que trascienden por mucho al sector agropecuario, que comprometen a toda la sociedad, que requieren una real y no impostada transformación del régimen político. ¿Hay en las partes en conflicto algún sector interesado en encarar esta transformación? ¿Estos conflictos están indicando una oportunidad histórica de transformación socioeconómica y política?

En el caso del conflicto "del campo" consideramos que se trató de un caso particular, parcial y una expresión concreta de lucha de poder entre sectores económicos dominantes. Alcanzamos esta conclusión al observar que: (i) los actores presentes en esta disputa eran muy diversos en sus tipos y características; (ii) la gran mayoría de los productores involucrados (ligados al modelo de agricultura familiar) no lograron finalmente beneficiarse con la medida reclamada por las entidades que "supuestamente" los representaban. A lo cual debemos sumar la gran cantidad de otros conflictos territoriales que se están dando en el país y no alcanzan ni remotamente la difusión que tuvo éste. El hecho mismo de haberse impuesto como una disputa que representaba generalizadamente al "campo" es una demostración de poder de parte de los sectores dominantes (vinculados al agronegocio).

En el caso de los otros conflictos analizados, observamos que el accionar organizado que se verifica en distintos ámbitos rurales, cuyos reclamos se escuchan en numerosos foros de distinto tipo, se oponen a las líneas que asume el modelo de desarrollo económico dominante, intentando generar otras alternativas. El futuro de otros caminos de "desarrollo" dependerá de la fuerza organizativa y del poder que los actores locales logren acumular y consolidar en sus luchas cotidianas. Porque no podemos ignorar la existencia de una relación de poder desigual entre los actores intervinientes en los territorios en general.
Las resistencias observadas en los casos expuestos se oponen en particular a dos tipos de fuerzas difíciles de controlar y/o superar. Por un lado, a procesos socioeconómicos asociados a dinámicas globales y promovidos por actores que presionan sobre otras formas de apropiación del espacio. Forestación, soja, minería, entre otras, son actividades de gran expansión en los '90, no sólo en Argentina sino en el mundo, habiendo contado con un marco jurídico y de política económica que se elaboró y/o adaptó para facilitar esa expansión. Resultando, finalmente, en una de las fuentes de tensión que sistemáticamente viene produciendo conflictos en ámbitos rurales del país. Quienes se postulan como los defensores de los intereses del campo, participan de ese modelo productivo, lo apoyan y lo promueven.

Por otro lado, a estructuras de poder fuertemente arraigadas en los ámbitos locales. Observamos que en ciertas circunstancias se activan o refuerzan relaciones de poder agudizando situaciones conflictivas, en muchos casos históricas. Esto es evidente en el conflicto por el agua en los Valles Calchaquíes y por la tierra en el nordeste de Misiones. Aunque los disparadores de estos conflictos son más recientes y asociados a políticas económicas de los '90 (el apoyo a la forestación en un caso, la descentralización en el uso del agua en el otro) su origen remite a raíces históricas vinculadas con las formas de acceso y control de recursos fundamentales como el agua y la tierra.

En todos estos casos de estudio, las estructuras de poder dominantes se mantienen y consolidan a lo largo de la historia de construcción de los territorios estudiados. Esto sucede porque el poder hegemónico dispone de variados procedimientos que concurren a naturalizar y legitimar las relaciones de poder preexistentes, entre ellos la conformación de leyes, normas y discursos que las avalan. En situaciones de conflicto, de enfrentamiento con el poder hegemónico, éste interviene de diferente modo para superar, detener o diluir dicho conflicto. En los casos analizados, en particular en el de Misiones, hemos observado que se buscaron mecanismos dirigidos a evitar su agudización y 
ampliación, entre ellos generar esperanzas de solución para los grupos movilizados, prometer pero retardar las decisiones, confundir y enfrentar a los actores. Todos ellos son variados modos para posponer la disputa, su resolución y, en el largo plazo y en algunas circunstancias, conseguir diluirla.

\section{Notas}

${ }^{1}$ Este artículo se enmarca en el contexto de los proyectos: PICT 0188 (FONCyT-Agencia), UBACYT F056 y PID 1879 -CONICET y BR/08/23 MINCYTCAPES.

2 Las retenciones son un impuesto a las exportaciones, en este caso de granos. Se trata de un instrumento de la política económica que genera ingresos públicos y regula el funcionamiento de ciertos mercados. En Argentina comenzó a aplicarse en la etapa ultraliberal del ministro Krieguer Vasena (1967) asociado a una devaluación del peso del $40 \%$ (lo que indudablemente alteró sustancialmente las relaciones entre mercado interno y externo al generar una renta extraordinaria para el sector exportador). Desde entonces continuaron regularmente, excepto el período de la convertibilidad 1992-2001. Las retenciones son una herramienta de regulación necesaria en un país agro exportador que comercializa en el mercado internacional los alimentos que consume. Con ellas es factible controlar que el alza internacional de los precios no afecte el mercado interno de productos de primera necesidad. En particular, en relación a la situación que nos ocupa, en marzo de 2008 el gobierno creó un nuevo mecanismo, conocido como "retenciones móviles" (consistente en una tasa que sube cuando el precio internacional crece y baja cuando éste desciende). Esta decisión se tomó en un momento en que los precios de los granos -y en especial la sojaestaban experimentando una considerable alza que no parecía tener límite.

3 Es el lapso de tiempo entre que se divulgó la resolución 125 , hasta que se trató y anuló su aplicación por rechazo del Congreso Nacional. El conflicto sin embargo continuó, aunque con otras características y menor virulencia

${ }^{4}$ Se denomina de esa manera al proceso de expansión de la producción y superficie implantada con soja en detrimento de otras actividades agropecuarias tradicionales, tanto en el área pampeana como en áreas extrapampeanas. El mismo es en realidad resultado de la "agriculturización" que viene experimentando el agro argentino desde la década de 1970, como resultado de los avances tecnológicos y de la mejora de los precios internacionales de las principales commodities producidos en el país (soja, maíz, trigo y girasol). Todo lo cual incrementó la rentabilidad de la producción de granos frente a la tradicional actividad ganadera.

${ }^{5}$ Múltiples investigaciones cualitativas en ámbitos locales dan cuenta de una diferenciación y polarización creciente entre inversores y productores grandes y sectores sistemáticamente excluidos y marginados de su actividad tradicional. La poca confiabilidad de los datos del Instituto Nacional de Estadística y Censos (desde su intervención en octubre de 2006 -Gobierno de Néstor Kirchner) dificultan dar cuenta de esta situación en términos cuantitativos.

${ }^{6}$ A pesar de su fortaleza política previa, y de haber ganado una elección nacional poco antes, el gobierno quedó debilitado. Y, en algún sentido, se mantuvo en vilo a la propia democracia, ya que detrás de la protesta se fortalecieron sectores conservadores sin poder político hasta entonces, muchos muy conocidos en la historia nacional por su accionar político regresivo y excluyente (como la oligarquía terrateniente representada en la Sociedad Rural).

7 Según las informaciones periodísticas, un 50\% de los manifestantes eran "autoconvocados" es decir no pertenecían a ninguna de las cuatro instituciones agrarias de la denominada Mesa de Enlace. 
Conflictos territoriales em

ámbitos rurales de la Argentina actual, pp. $197-218$

${ }^{8}$ Cabe aclarar que entre los pequeños y medianos productores eran mayoría los de zonas ligadas a la producción de granos (los más afectados directamente por las retenciones móviles). En cuanto a la participación de los trabajadores era minoritaria (dada la baja intensidad en el uso de fuerza de trabajo de la producción granaria). De todos modos, debe tenerse en cuenta que para éstos se estaba condicionando su fuente de trabajo.

9 Se trata de una de las principales empresas agroindustriales productoras de aceite del país. ${ }^{10}$ De hecho, mientras que en el país la disminución de EAPs fue del $20 \%$, en el área pampeana alcanzó casi el $30 \%$. La mayor parte de esa disminución corresponde en ambos casos a EAPs de hasta 100 ha de superficie (Slutzky, 2007)

${ }^{11}$ Centro-este y norte de la provincia de Buenos Aires y sur de Santa Fe dónde, consecuentemente, también están los propietarios de las tierras mas valorizadas (a un precio por hectárea que ronda los u\$s10.000).

12 Un ejemplo muy conocido de esta modalidad de producción es el grupo "Los Grobo", de trascendencia más allá de las fronteras argentinas. Con más de $150.000 \mathrm{Ha}$ en explotación en el país, su principal referente, Gustavo Grobocopatel, se ha identificado como un "sin tierra", porque no es el dueño de las grandes extensiones que explota (La Nación, 2/12/2007).

${ }^{13}$ Por ejemplo, en la zona núcleo maicera (norte de la provincia de Buenos Aires) el precio de arriendo por hectárea para soja y maíz alcanzó para la campaña 2008-2009 entre 530 y 620 dólares. E incluso en las zonas menos valorizadas de la provincia, los precios alcanzan los 200 dólares por hectárea (Compañía Argentina de Tierras S.A, http://www.cadetierras.com.ar/ est alquileres.asp, 26/11/2009).

${ }^{14}$ Esto fue lo que finalmente sucedió cuando este conflicto se dirimió en el Congreso y en la votación en la Cámara de Senadores perdió el Gobierno. Entonces se dio marcha atrás con la medida de aplicar las retenciones móviles. Y, a pesar que éste había sido el eje del reclamo, los pequeños productores no resultaron beneficiados por esta anulación de la medida original. Por el contrario terminaron perjudicados, porque perdieron la oportunidad de recibir un tratamiento diferencial. Lo cual fue aún más notorio cuando poco tiempo después cayó el precio de la soja en el mercado internacional y las retenciones móviles "hacia abajo" les hubiera sido beneficiosa. Es decir, de aquella "resolución" de este conflicto en el que participaron grandes y pequeños productores, sólo los primeros se beneficiaron con la decisión del Congreso de anular la medida gubernamental.

${ }^{15} \mathrm{Se}$ trata de las cuatro entidades que conforman la Comisión de Enlace: Sociedad Rural Argentina (SRA), Confederación Intercooperativa Agropecuaria (CONINAGRO), Confederaciones Rurales Argentinas (CRA) y Federación Agraria Argentina (FAA). Las tres primeras, son organizaciones de representación de intereses de productores medianos y grandes del área pampeana, fundamentalmente. La última, es una organización de representación de intereses de pequeños y medianos productores también del área pampeana, aunque hace unos años comenzó ampliar su base, difundiéndose hacia otras áreas del país y hacia productores más pequeños y marginados.

16 En este mapa aparecen representados los que en esta investigación denominamos "conflictos territoriales". La fuente señalada (Domínguez, 2010) parte de una definición similar de dichos conflictos, que fueron identificados a partir de la consulta de fuentes periodísticas o de páginas de Internet de organizaciones campesinas, durante los años 2007 y 2008. La representación del conflicto "del campo" se realizó a partir de la identificación de los cortes de ruta que se realizaron durante el paro agropecuario que se extendió por 21 días entre el $14 / 3$ y el $3 / 4$. Se seleccionaron algunos días representativos del período más álgido del conflicto $(17 / 3,19 / 3,21 /$ $3,23 / 3$ y $31 / 3)$. 
${ }^{17}$ En algunos contextos rurales latinoamericanos, por ejemplo, los pequeños productores reaparecen como actores con poder de movilización social enfrentados al modelo hegemónico. Ejemplo de esto es el surgimiento de importantes movimientos campesinos como el Ejército Zapatista de Liberación Nacional (EZLN) en México, el Movimiento de los Sin Tierra (MST) en Brasil y los movimientos indigenistas en Bolivia, Ecuador y Colombia.

${ }^{18}$ Un mayor desarrollo del mismo puede consultarse en Manzanal, 2007; Manzanal et al 2009 y Manzanal et al 2010.

${ }^{19} \mathrm{Se}$ trata de: un conflicto por la reapertura de una mina de uranio y un conflicto por el agua de riego, ambos en la cuenca de los Valles Calchaquíes (Salta) y un conflicto por tierra en el nordeste de Misiones. Algunos avances de estas indagaciones se encuentran en Bonzi (2010); Villarreal (2010), Arzeno y Ponce (2010) y Manzanal et. al (2010).

${ }^{20} \mathrm{La}$ información sobre estos conflictos fue extraída principalmente de fuentes periodísticas, tanto de diarios nacionales como provinciales. Diarios Nacionales: La Nación, Clarín, Pagina 12. Diarios Provinciales: El Tribuno de Salta, Nuevo Diario de Salta, El Territorio (de Misiones). Para la sistematización y análisis de los conflictos se tuvieron en cuenta una serie de variables, entre ellas: (i) el tema: grandes ejes problemáticos surgidos de las demandas de los actores, en torno a la cuales se gestó el conflicto; (ii) la demanda: el objeto por el cual los actores demandantes reclaman; (iii) los actores demandantes y demandados.

${ }^{21}$ Son reclamos por la construcción o mejora de cierta infraestructura, o bien por el control y manejo de la ya existente.

${ }^{22}$ Anteriormente a dichas reformas, la Administración General de Aguas de Salta (AGAS) era la: "institución provincial encargada de actuar con poder de policía en el cumplimiento de prácticas esenciales para el funcionamiento del sistema de irrigación, como son el destome, el respeto por el turnado entre los productores de un mismo sistema de riego, el pago del canon de riego, etc." (Villarreal, 2010: 190). Dicha institución estuvo en funcionamiento entre 1946 y 1998.

${ }^{23}$ Y sustentada en la sanción de un conjunto de leyes y decretos que modificaron el Código Minero y el sistema jurídico que regulaba la minería en Argentina.

${ }^{24}$ Esto queda evidenciado en el hecho que las protestas son individualizadas y adjudicadas a unos pocos actores identificados como foráneos, divulgando que "la mayoría de los Autoconvocados son artesanos venidos de otras provincias y radicados en la zona en distintos momentos". Además, "a los pueblos indígenas se los estigmatiza racialmente menospreciando sus conocimientos y señalándolos como ignorantes o supersticiosos" (Manzanal et al 2010).

${ }^{25}$ Se trata de empresarios forestales locales que se oponen a la compra de grandes extensiones de tierra por parte de una de las principales empresas de capitales extranjeros dedicada a la forestación en la provincia (Alto Paraná).

${ }^{26} \mathrm{La}$ ocupación de tierras privadas del nordeste de Misiones es resultado de una serie de procesos, algunos de carácter histórico. (i) El desarrollo de la explotación del bosque nativo desde la década de 1950 y el surgimiento de numerosos obrajes. Estos permitían y alentaban la instalación de los empleados y sus familias en las propiedades, ya que se trataba de una estrategia de las empresas para asegurarse un contingente de mano de obra barata, cuando así lo requirieran (Kostlin, 2005). (ii) El avance de la frontera agrícola. En el nordeste provincial este proceso se inicia hacia la década de 1960 a través de la ocupación espontánea, en tierras fiscales, de agricultores del sur de la provincia y de Brasil (estos últimos expulsados por procesos de avance del capitalismo agrario en las colonias del sur de dicho país). Cuando hacia la década de 1980 se agotó la reserva de tierras fiscales, se inicia la ocupación espontánea de 
Conflictos territoriales em

ámbitos rurales de la Argentina actual, pp. $197-218$

tierras privadas del nordeste, proceso potenciado por la expansión de la actividad tabacalera en esa época (Schiavoni, 2005). Y (iii) la instalación de población urbana de origen campesino en el momento de la crisis económica de la década de 1980, en búsqueda de una alternativa de subsistencia.

${ }^{27}$ La promoción de la forestación proviene de larga data, pero se incrementó durante la década de 1990. En 1992 se inició el Régimen de Promoción de Plantaciones Forestales, que reactivó los incentivos para la forestación. En 1995 se puso en marcha el Plan Nacional de Desarrollo Forestal y en 1999 se dictó la ley 25.080 de Inversiones para Bosques, que preveía subsidios para plantaciones hasta el 2009 (Kostlin, 2005: 29). El importante crecimiento de las plantaciones forestales en la provincia aparece reflejado en el hecho que éstas pasaron de 77.793 ha en 1972 a 384.948 ha en 2002: $500 \%$ de incremento en 30 años.

${ }^{28}$ En particular cabe destacar el caso de la empresa Alto Paraná, comprada en el año 1996 por la empresa Celulosa Arauco, de capitales chilenos. Esta concentra 232.000 ha de tierras en Misiones, una de las provincias más pequeñas del país.

${ }^{29}$ Estos temas se encuentran desarrollados con mayor detalle en Arzeno y Ponce (2010).
${ }^{30}$ En efecto, de acuerdo a lo informado por un alto funcionario del gobierno provincial en septiembre de 2009, se espera llegar a un "acuerdo de partes" con los propietarios y no ejecutar la expropiación. La idea es no sentar un precedente en la provincia que pueda ser seguido por los otros miles de productores con problemas de tenencia. Asimismo, se sostiene que el precio que pretenden los propietarios por sus tierras eleva a cifras millonarias el desembolso de dinero que el Gobierno provincial debería hacer. Lo cual es considerado "excesivo".

31 Se trata de la empresa Puente Alto S.A., que compró la propiedad Intercontinental Compañía Maderera, por la quiebra de la empresa ocurrida varios años antes.

${ }^{32}$ En general los productores movilizados por la lucha por la tierra, plantean el deseo de "liberarse" de la producción del tabaco, no sólo debido a la sujeción que implica en relación con las empresas tabacaleras, con quienes establecen lazos de agricultura de contrato, sino además por la mayor conciencia existente en relación con los problemas de salud que genera el proceso de producción de este cultivo (al respecto ver Baranger -Coord.- 2007)

\section{Bibliografia}

Arzeno, Mariana y Ponce, Mariana (2010) "El conflicto sin fin. Negociaciones y disputas en torno a la aplicación del Plan de Arraigo y Colonización en tierras privadas del nordeste de Misiones". Manzanal, M. y Villarreal, F. (Org.) El desarrollo y sus lógicas en disputa en el norte argentino. Buenos Aires: Ediciones CICCUS.

Ataide, Soraya y González, Fernando (2010) "Anexo. Relevamiento de los principales conflictos territoriales en las provincias de Salta y Misiones (1990-2008)". En: Manzanal, Mabel y Villarreal, Federico (Org.) El desarrollo y sus lógicas en disputa en territorios del Norte Argentino.
Ediciones CICCUS, Buenos Aires. ISBN 978-9871599-04-2.

Baranger, Denis, Coord. (2007) Tabaco y Agrotóxicos. Un estudio sobre productores de Misiones. Edit. Universitaria, Universidad Nacional de Misiones, Posadas.

Bonzi, Leandro (2010) "Disputas territoriales en torno a la actividad minera en los Valles Calchaquíes, Salta. El caso de la mina Don Otto". En: Manzanal, Mabel y Villarreal, Federico (Org.) El desarrollo y sus lógicas en disputa en territorios del Norte Argentino. Ediciones CICCUS, Buenos Aires. ISBN 978-987-1599-04-2. 
Bourdieu, Pierre (2006), "Los modos de dominación", en Bourdieu P. (2006), Como del Poder y Reproducción Social, Ferreyra Editor, Córdoba.

Haesbaert, Rogerio (2006 [2004]), O mito da desterritorializaçao. Do "fim dos territorios" à multiterritorialidade, Bertrand Brasil, Rio de Janeiro, 395 pág.

Kostlin, Laura (2005) Voces y silencios en la lucha por la tierra en Misiones. Tesis de Grado. Universidad Nacional de Misiones, Departamento de Antropología Social, Misiones. 110 p.

Lopes de Souza, Marcelo (1995). "O territorio: sobre espaço e poder, autonomia e desenvolvimento". En: De Castro, I.; da Costa Gómez, P. y Lobato Correa, R. Geografia: conceitos e temas. Río de Janeiro, Bertrand Edit.

Manzanal, Mabel (2007) "Territorio, poder e instituciones. Una perspectiva críticfa sobre la producción del territorio". En Manzanal Mabel, Mariana Arzeno y Beatriz Nussbaumer (comp.). Territorios en construcción: actores, tramas y gobiernos: entre la cooperación y el conflicto. CICCUS, Buenos Aires. pp. 135-167.

Manzanal, Mabel; Arqueros, M. X.; Arzeno, M. y Nardi, M.A. (2009) "Desarrollo territorial en el norte argentino. Una perspectiva crítica". En: Eure, 35 (106), Santiago de Chile.

Manzanal, Mabel y Villarreal, Federico Org. (2010) El desarrollo y sus lógicas en disputa en territorios del Norte Argentino. Ediciones CICCUS, Buenos Aires. ISBN 978-987-1599-04-2.

Manzanal, M, Arzeno M, Bonzi L., Ponce M, y Villarreal F. (2010), "Disputas por los recursos territoriales en el norte argentino. Diversas expresiones de lucha, dominación y poder", en Manzanal M. y Neiman G. (Org.) La agricultura familiar en los países del Cono Sur: situación y perspectivas, Edic. CICCUS, Buenos Aires, en prensa.
Santos, Milton (2009[1996]) A Natureza do Espaço. San Pablo: EDUSP.

Schiavoni, Gabriela (1995) "Gestión doméstica y capitalización de pequeñas explotaciones: los productores de la frontera agraria de Misiones (Argentina)". Hugo Trinchero (comp.) Producción doméstica y capital. Estudios desde la antropología económica. Buenos Aires: Editorial Biblos.

Schiavoni, Gabriela (2005), "La construcción de los 'sin tierra' en Misiones, Argentina", en Revista Theomai, N 12, Universidad Nacional de Quilmes, Buenos Aires.

Slutzky, Daniel (2005) "Los conflictos por la tierra en un área de expansión agropecuaria del NOA. La situación de los pequeños productores y los pueblos originarios" en Revista Interdisciplinaria de Estudios Agrarios, № 23, $2^{\circ}$ semestre, p. 59100.

Slutzky, Daniel (2007) "Situaciones problemáticas de tenencia de la tierra en Argentina". Secretaría de Agricultura, Ganadería, Pesca y Alimentos, Serie Estudios e Investigaciones $n^{\circ} 14$, Buenos Aires.

Villarreal, Federico (2010) "El conflicto entre los productores de San Carlos (Salta) por el agua del río Calchaquí" Manzanal y Villarreal (Org.) (2010) El desarrollo y sus lógicas en disputa en territorios del Norte Argentino. Ediciones CICCUS, Buenos Aires. ISBN 978-987-1599-04-2. P. 175-196.

\section{Fuentes Mapa 1:}

Domínguez, Diego (2010) "La territorialización de la lucha por la tierra en la Argentina del bicentenario". En: VII Jornadas de Investigación y Debate: Conflictos rurales en la Argentina del Bicentenario. Significados, alcances y proyecciones. Universidad Nacional de Quilmes, Quilmes.

Diario La Nación. Ediciones de los días 17, 19, 21, 23 y 31 de marzo de 2008. 